\title{
Nonlinear changes in the activity of the oxygen- dependent demethylase system in Rhodococcus erythropolis cells in the presence of low and very low doses of formaldehyde
}

\author{
Elżbieta Malarczyk*, Marzanna Pazdzioch-Czochra, Marcin Grąz, Janina Kochmańska-Rdest and
}

Anna Jarosz-Wilkołazka

\begin{abstract}
The effect of exogenous, highly diluted formaldehyde on the rate of demethylation/re-methylation of veratric acid by the bacteria Rhodococcus erythropolis was studied using electrophoretic and microscopic techniques. The activity of 4-O-demethylase, responsible for accumulation of vanillic acid, and the levels of veratric and vanillic acids were determined using capillary electrophoresis. Formaldehyde was serially diluted at 1:100 ratios, and the total number of iterations was 20. After incubation of the successive dilutions of formaldehyde with the bacteria, demethylase activity oscillated in a sinusoidal manner. It was established using capillary electrophoresis that methylation of vanillic acid to veratric acid occurred at a double rate, as shown by the doubled fluctuation in the concentration of veratrate. There were also changes in the NADH oxidase activity, which is associated with methylation processes. Microscopic observations revealed the presence of numerous enlarged vacuoles in bacterial cells during the accumulation of large amounts of vanillic acid, and their disappearance together with a decrease in 4-Odemethylase activity. The presented results give evidence for the ability of living cells to detect the presence of submolecular concentrations of biological effectors in their environment and provide a basis for a scientific explanation of the law of hormesis and the therapeutic effect of homeopathic dilutions.
\end{abstract}

Keywords: formaldehyde, O-demethylases, homeopathy, Rhodococcus erythropolis, low doses

\section{Introduction}

Demethylation processes are widespread in all living organisms. They regulate replication and translation processes via methylation and demethylation of histones. In bacteria and fungi, they take an active part in transformations of phenolics, which form the basis of synthesis and biodegradation of lignin in plant tissues and humic acids in soil. Transformations of phenolics are strongly associated with secondary metabolism.

Methylathion is based on a reversible substitution of hydrogen with a $-\mathrm{CH}_{3}$ group at an electrophilic atom of nitrogen, oxygen, or sulfur. Demethylation refers primarily to the removal of a $-\mathrm{CH}_{3}$ group from a methoxy group $\left(\mathrm{O}-\mathrm{CH}_{3}\right)$, an $\mathrm{N}$-methyl group $\left(\mathrm{N}-\mathrm{CH}_{3}\right)$ or an $\mathrm{S}$ -

\footnotetext{
* Correspondence: malar@poczta.umcs.lublin.pl
} Biochemistry Department, UMCS, Lublin, Poland methyl group (-S-CH 3 , which leads to the liberation of formaldehyde (FA) [1]. During distribution of methyl groups in numerous cellular processes in animals, plants, and bacteria, an important role is played by enzymes, which facilitate the transfer of the one-carbon $\left(-\mathrm{CH}_{3}\right)$ radical. The main substrates for these processes are the amino acids arginine and lysine [2]. Proteins rich in these amino acids, such as histones, owing to the proper distribution of methyl groups in them, determine the direction of many vital reactions, such as DNA activation [3,4]. Methylation of other proteins is responsible for chemotaxis in bacteria [5]. Also very important are transformations of natural catecholamines in higher animals, in which methylation of phenolic substances serves life-sustaining bioinformation purposes. It is phenolics and their methylated counterparts, methoxyphenols - which under aerobic conditions undergo 
enzymatic catalysis with the participation of O-demethylases - that constitute an important group of substrates for methylation and demethylation processes in bacterial and fungal cells [6-8]. Demethylase systems cooperate with a whole range of co-factors, including the FA molecule, which initiates the transformations referred to as the formaldehyde cycle [9]. Due to its high reactivity, this one-carbon molecule appears as a product of demethylation and, simultaneously, as a substrate for methylation. In lignin-degrading and humus-forming bacteria, among them Rh. erythropolis [10], methylation/ demethylation processes are used to obtain recalcitrant carbon compounds from wood and lignin and thus contributing to detoxification of the environment $[11,12]$. Very similar processes of degradation of veratrate, vanillate, and isovanillate with the cooperation of $3 \mathrm{O}$ - and $4 \mathrm{O}$-oxygenases and $\mathrm{NAD}(\mathrm{P}) \mathrm{H}$ and $\mathrm{HCHO}$ have been described by Providenti et al. $[13,14]$ for the bacteria Comamonas testosteroni BR 6020 (formerly Pseudomonas). In aerobic conditions, these processes often become cyclic, and FA and its active states seem to play an important regulatory role in them [15]. In 1998, in a study of transformations of methoxyphenols in fungi and ligninolytic bacteria [16], we described the cyclic process of demethylation/methylation of veratric acid and vanillic acids in Rh. erythropolis [17], coupled with the activity of membrane bound NADH oxidase [18] and periodic reconstruction of the pool of veratric acid as a result of alternate activation of methylase and demethylase activities in these bacteria combined with changes in the levels of oxygen uptake. Figure 1 shows a hypothetical mechanism for these processes.

As the diagram shows, a single addition of potassium veratrate to the bacterial cell culture of Rh. erythropolis was enough to initiate those cyclic transformations. We concluded that the presence of the hard-to-assimilate veratric acid triggered in the investigated cells processes which were almost analogous to respiratory burst (MAX state in the diagram). During the violent oxygen uptake, $\mathrm{NADH}$ oxidase-mediated release of reactive oxygen

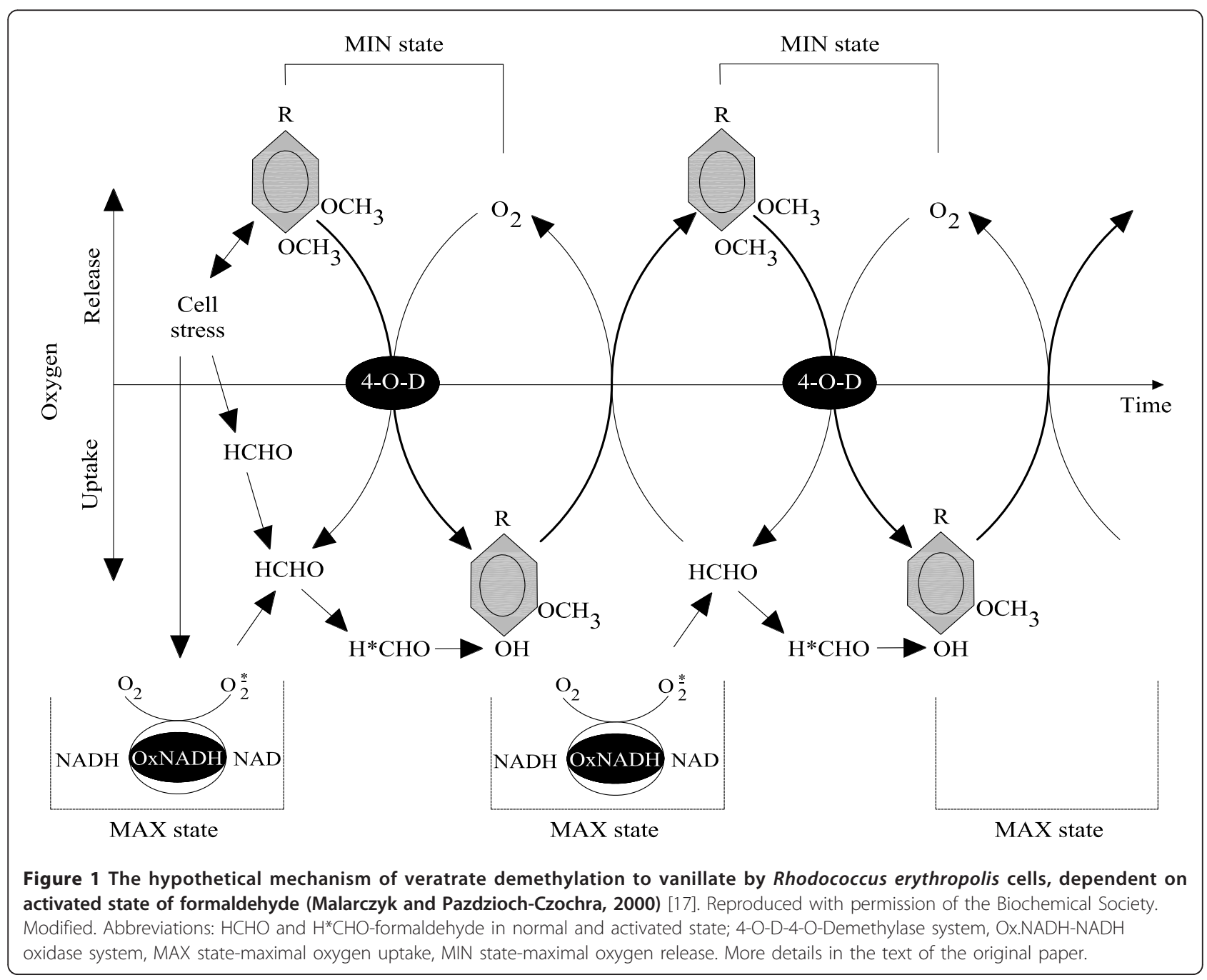


species into the medium of $R h$. erythropolis cells was observed. The ROS activated FA produced as a result of veratrate demethylation (Figure 1). Owing to this activation, FA became particularly reactive with vanillic acid and was able to convert it again into veratric acid via the path of non-enzymatic methylation. Thus, while demethylation is connected with the presence of an active form of the enzyme 4-O-demethylase, methylation seems to occur spontaneously using free-radical energy, which activates FA as a donor of a methyl group [19].

The periodic and spontaneous character of the observed changes in the activity of veratrate O-demethylases, measured as the amount of vanillic acid in the reaction medium, was clearly stimulated by the presence of FA and was associated with the NADH oxidase activity. The above relationships testify to the existence in the examined bacterial cells of autoregulatory mechanisms, the molecular aspects of which remain to be explained. Those findings became an incentive for further observations of the interrelationship between the two enzymes and the level of FA, this time with the focus on the exogenous effect of this compound. The experiments presented below were carried out on the basis of previous work on fungal oxidases [20], fungal laccase [21] and plant peroxidase [22,23], and the changes in their activities in the presence of low doses of phenolic co-factors. The present study provided new data relating to the influence of different FA dilutions on changes in the activity of veratrate O-demethylase and the cooperating NADH oxidase in the cells of $R h$. erythropolis.

\section{Materials and methods Biological material}

Cells of Rhodococcus erythropolis (previously Nocardia sp DSM 1069) were cultivated on a liquid medium according to [17]. Cultures were grown in $250 \mathrm{ml}$ conical flasks filled with $100 \mathrm{ml}$ medium on a rotary shaker at $30^{\circ} \mathrm{C}$. The cells were collected in the mid-logarithmic phase of growth by centrifugation at $10000 \times \mathrm{g}$, and a suspension of optical density A660 = 1 was prepared with $0.06 \mathrm{M}$ phosphate buffer, $\mathrm{pH}$ 7.4.

\section{Formaldehyde dilutions}

A $1 \mathrm{M}$ solution of FA in phosphate buffer, $\mathrm{pH} 7.4$, was diluted at a 1:100 ratio in distilled water and in $75 \%$ ethanol by transferring $0.1 \mathrm{ml}$ of each successive FA dilution into $9.9 \mathrm{ml}$ of diluents and dynamically shaking $[22,23]$. After 20 transfers, two series of dilutions of FA solutions, named from $n=1$ to $n=20$, were obtained: one in distilled water and the other in $75 \%$ ethanol. As a control, two independent series of pure water and $75 \%$ ethanol were prepared by shaking, in an analogous manner to that described for the dilutions of formaldehyde.
After $\mathrm{n}$ transfers (dilution steps) the FA concentration is equal

$$
c_{n}=c_{0} / r^{n}
$$

where

$\mathrm{c}_{0}$ denotes initial concentration, and $\mathrm{r}$ denotes dilution ratio.

In our case $c_{0}=1 \mathrm{M}$ and $\mathrm{r}=100$ we have

$$
c_{\mathrm{n}}=10^{-2 \mathrm{n}}
$$

So, $\mathrm{n}$ is a unit of the logarithmic concentration scale

$$
\mathrm{n}=-\left[\log \left(\mathrm{c}_{\mathrm{n}} / \mathrm{c}_{0}\right) / \log (\mathrm{r})\right]
$$

Here we have $\log (\mathrm{r})=\log (100)=2$ and

$$
\mathrm{n}=-\log \left(\mathrm{c}_{\mathrm{n}} / 1\right) / 2=-1 / 2 \log \left(\mathrm{c}_{\mathrm{n}}\right)
$$

with concentration $\mathrm{c}_{\mathrm{n}}$ in $\mathrm{mol} / \mathrm{liter}$.

In our case only integer values of $\mathrm{n}$ make sense. So we have to stress that in all our Figures the wave-like lines are drawn only for convenience to indicate the points belonging to a given series.

\section{Incubation of FA dilutions with Rh. erythropolis cells}

A cell suspension with an optical density of 1 at 660 $\mathrm{nm}$ was supplemented with veratric acid $(200 \mu \mathrm{l} 2 \%$ acid per $10 \mathrm{ml}$ suspension) and divided into twenty one $10 \mathrm{ml}$ aliquots. Each aliquot was then supplemented with $200 \mu \mathrm{l}$ of a selected dilution of FA in ethanol, water, or an appropriate control. The suspensions were left to stand at room temperature for a variable period of time, dependent on the type of experiment. After incubation, the samples were centrifuged, and the cell pellet was separated from the supernatant. The cell pellet was used to determine NADH oxidase activity, and the supernatant was used to determine the level of phenolic acids.

\section{Determination of demethylase activity in a colorimetric test}

In the supernatant, after centrifugation of cells, two main products of veratrate demethylation, vanillic and isovanillic acids, were determined in a colorimetric test with DASA (diazosulphamide) [10]. $0.2 \mathrm{ml}$ of each sample was mixed with $0.2 \mathrm{ml}$ of $2 \%$ sulfanilamide solution in $10 \%$ hydrochloric acid followed by $0.2 \mathrm{ml}$ of $5 \%$ $\mathrm{NaNO}_{2}$. After $1 \mathrm{~min}$, the reaction mixture was neutralized with $1 \mathrm{ml}$ of $20 \% \mathrm{Na}_{2} \mathrm{CO}_{3}$, and absorbance at 500 $\mathrm{nm}$ (for vanillic acids) was measured. The amount of vanillic acids was calculated based on a calibration curve $(y=6.85 x-0.0218, R 2=0.999)$. All the measurements were done in triplicate. Data were obtained for the same set of samples. 


\section{Capillary electrophoretic determination of phenolic substances}

Because the colorimetric test provided no information on the qualitative and quantitative composition of the mixture of phenolic substances, the supernatant, after separation of Rh. erythropolis cells, was used to establish the amount and type of the phenolic products of demethylation using micellar electrokinetic chromatography (MEKC). Analyses of the supernatants obtained after incubation of the water and ethanol dilutions of FA with $R h$. erythropolis cells (see Biological Material) were performed using Thermo Capillary Electrophoresis, Crystal 100, (Thermo Separation Products, San Jose, USA) equipped with a UV-Vis diode array detector. Separations were carried out using a $50 \mu \mathrm{m}$ ID fused silica capillary with a total length of $70 \mathrm{~cm}(44 \mathrm{~cm}$ to the detection window). The applied voltage was $29 \mathrm{kV}$, and the capillary temperature was maintained at $30^{\circ} \mathrm{C}$. Samples were injected hydrodynamically for 1 second, and detection was performed at $210 \mathrm{~nm}$. Separation was done in a buffer prepared by dissolving boric acid (100 $\mathrm{mM}$ ) and sodium dodecyl sulfate (SDS, $100 \mathrm{mM}$ ) in MilliQ water. The buffer, pH 9.3, was adjusted using $\mathrm{NaOH}$. Peak identification was done by spiking with commercially available veratric, vanillic, isovanillic, and protocatechuic acids and catechol, as potential products of demethylation. The capillary was conditioned using 1 $\mathrm{M} \mathrm{NaOH}$ by $10 \mathrm{~min}$. and $5 \mathrm{~min}$. washing with 0.1 $\mathrm{NaOH}$ before filling with buffer at the start of each day of analysis. Before each analysis, the capillary was conditioned with $1 \mathrm{M} \mathrm{NaOH}, 0.1 \mathrm{M} \mathrm{NaOH}$, MilliQ water, and filling buffer, 2 min. each.

\section{Determination of NADH oxidase activity}

The NADH oxidase activity was determined for the cell membrane fraction, following homogenization of cell pellet in a chilled mortar after centrifugation of $20 \mathrm{ml}$ of cell suspension. The membrane pellet was resuspended in 0.4 M acetate buffer, $\mathrm{pH}$ 5.0. The activity was determined by measuring oxygen uptake with an oxygen electrode, according to Vianello and Macri [24], in the presence of NADH. A pellet of cells which had no contact with veratrate was used as a control. $400 \mathrm{mM}$ of acetate buffer, $\mathrm{pH} 5.5$, was mixed with $1.26 \mathrm{M}$ saccharose and $0.5 \mathrm{ml}$ of sample, and $4 \mathrm{mM} \mathrm{NADH}$ was added at the start. The NADH oxidase activity was expressed as oxygen uptake $(\mu \mathrm{M} / \mathrm{ml})$.

\section{Electron microscopy}

Electron microscopy was carried out after embedding the cells in a mixture of $2 \%$ paraformaldehyde and $2.5 \%$ glutaraldehyde in cacodylic buffer, $\mathrm{pH}$ 7.4. For a better contrast, $1 \% \mathrm{OsO}_{4}$ in cacodylic buffer and $0.5 \%$ uranyl acetate in water were used. The cells were dehydrated in ethanol (30\% to $100 \%$ ethanol solutions) at room temperature and exposed to a propylene oxide concentration series, changing gradually from alcohol into pure oxide.

Spurr Low Viscosity resin was used to prepare ultrathin sections on an ultramicrotome (Reichert Ultracut S). Observations were made using a Tesla BS-500 microscope.

\section{Results}

\section{The course of demethylation of veratric acid}

Demethylation of veratric acid by Rhodococcus erythropolis turned out to be a diverse process, both in terms of the formaldehyde dilutions used and the time of incubation of cells with the substrate. The results provided clear evidence that the level of demethylation varied quantitatively depending on the dilution of formaldehyde. The curve obtained for water dilutions of FA showed slightly higher demethylation values than an analogous curve for ethanol solutions. Values obtained for both controls indicated no changes in demethylase activity (Figure 2). For both diluents, maximum demethylation was observed at formaldehyde dilutions $n$ $=6$ and $\mathrm{n}=16$, and minima corresponded to dilutions $\mathrm{n}=1, \mathrm{n}=10-11$, and $\mathrm{n}=20$. In 10-hour incubation experiments, only the ethanol series of FA dilutions was used so that sterile conditions could be maintained.

In a following experiment, the optimal time of incubation was determined for maximally and minimally active dilutions of the ethanol series. For this purpose, samples of incubating suspensions were taken every two hours, with measurements being done for 10 hours. The activity over time are shown in a $2 \mathrm{D}$ version (Figure 3 ) and a $3 \mathrm{D}$ version (Figure 4 ).

The results showed that the most effective time for demethylation of veratric acid by Rhodococcus erythropolis was 6 hours, for both activating dilutions ( $\mathrm{n}=5$ and 6) and inhibiting ones ( $\mathrm{n}=15$ and 16) (Figure 3 and 4).

\section{Qualitative and quantitative determination of demethylation products}

DASA is used to determine the amounts of those products of veratrate demethylation which have free $\mathrm{OH}$ groups, but does not allow one to qualitatively discriminate among them or to measure the concentration of veratric acid, which does not contain phenolic groups and, therefore, cannot be registered by the diazosulfanilamide method. To obtain those data, capillary electrophoretic determination of phenolic substances was performed. The use of this method made it possible both to establish the level of veratric acid and to discriminate between the two vanillic acids (Figure 5). Measurements were done for both FA dilution series after 6 hours of incubation (Figure 6 and 7). 


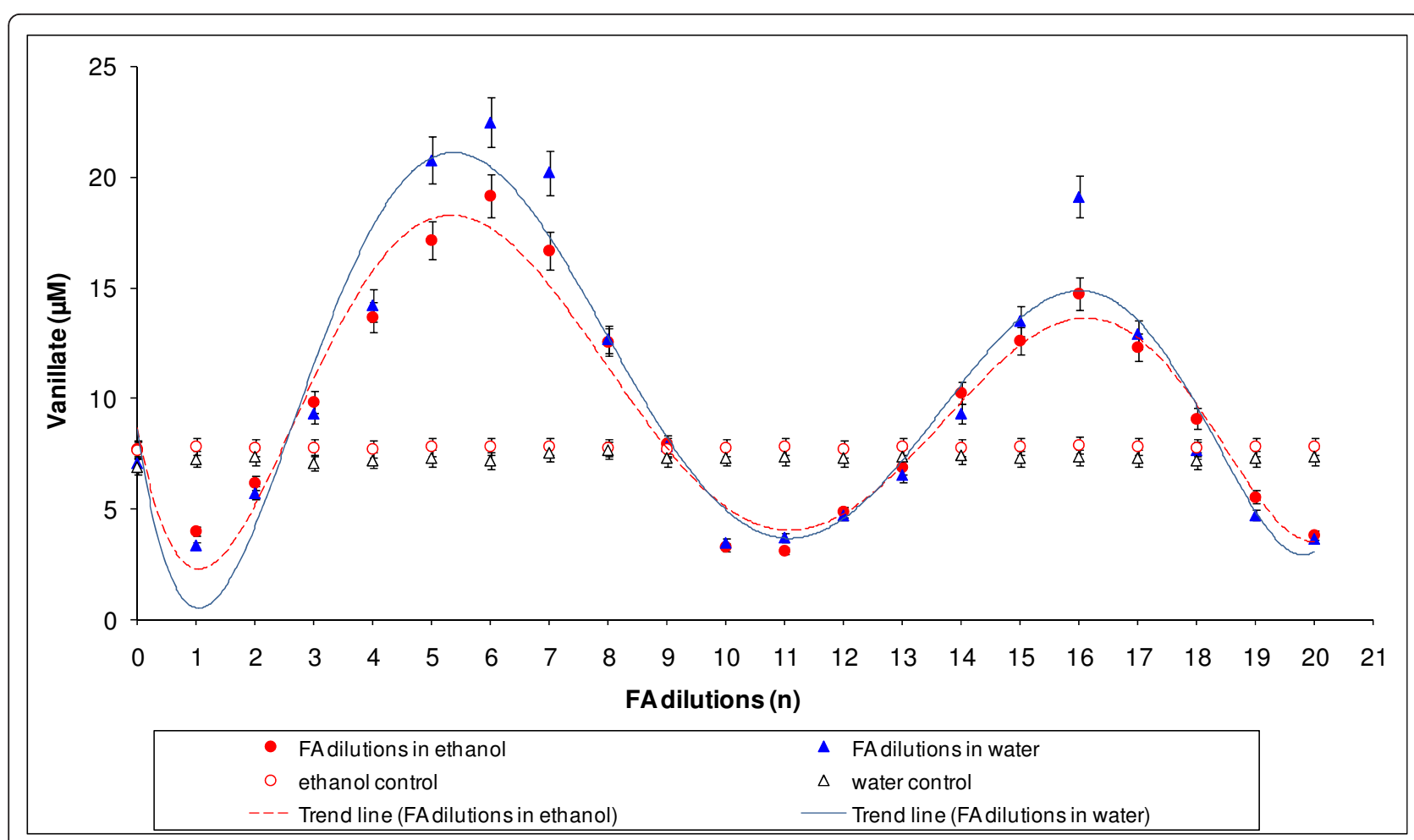

Figure 2 The demethylation of veratric acid by Rhodococcus erythropolis cells after 6-hour incubation with successive FA dilutions in water or in $75 \%$ ethanol, together with control values for water and $75 \%$ ethanol.

The MEKC measurement revealed the presence of only one product in the reaction environment - vanillic acid. Neither isovanillic acid nor catechol, which theoretically could accompany demethylation of veratric acid, was found. Changes in the concentration of vanillic acid and corresponding concentrations of veratric acid are shown in Figures 6 and 7.
The nearly exclusive presence of vanillic acid in the incubation medium pointed to the type of demethylase which was activated as a result of incubation of Rhodococcus cells with selected formaldehyde dilutions. The enzyme was 4-O-demethylase, which converted veratric acid into vanillic acid. In experiments with dilutions of the ethanol series, there appeared a clear quantitative

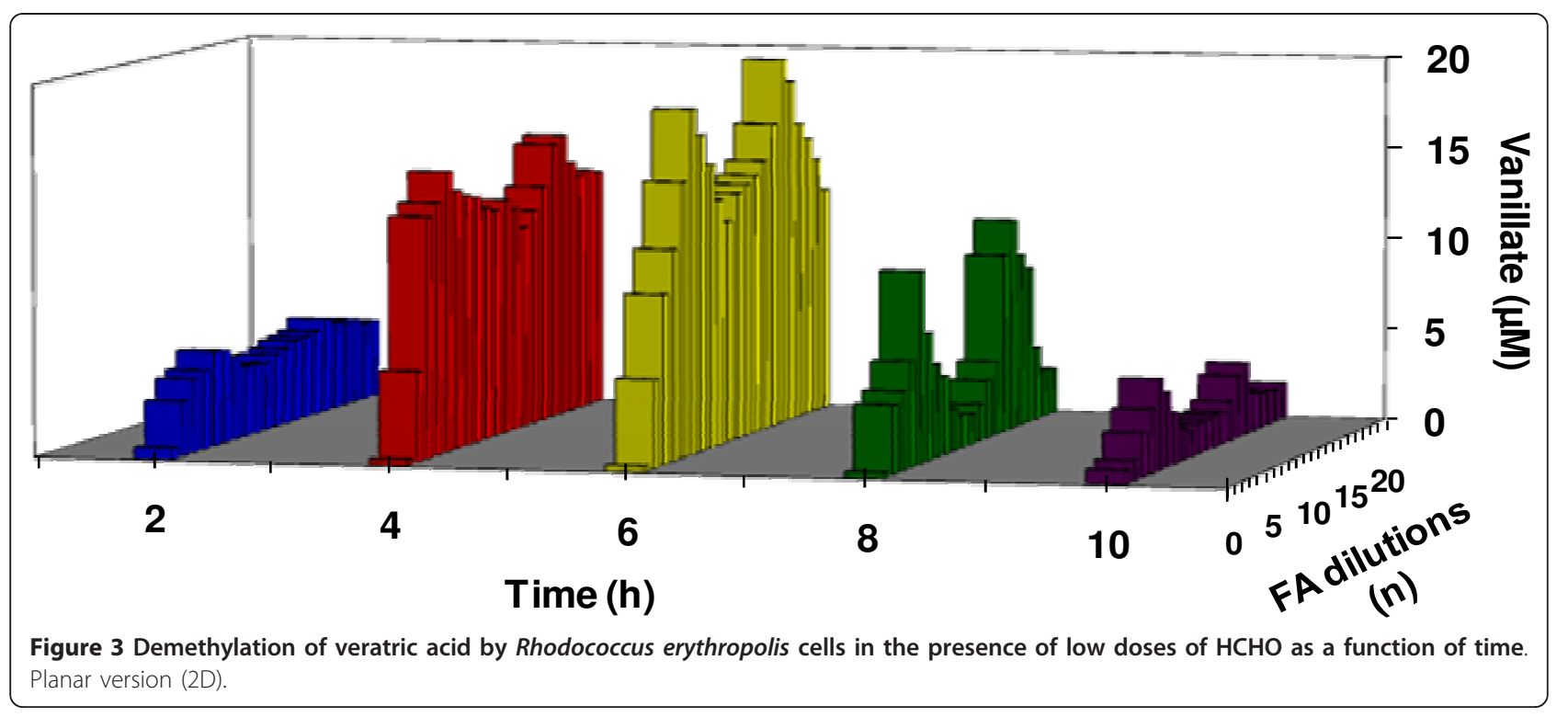




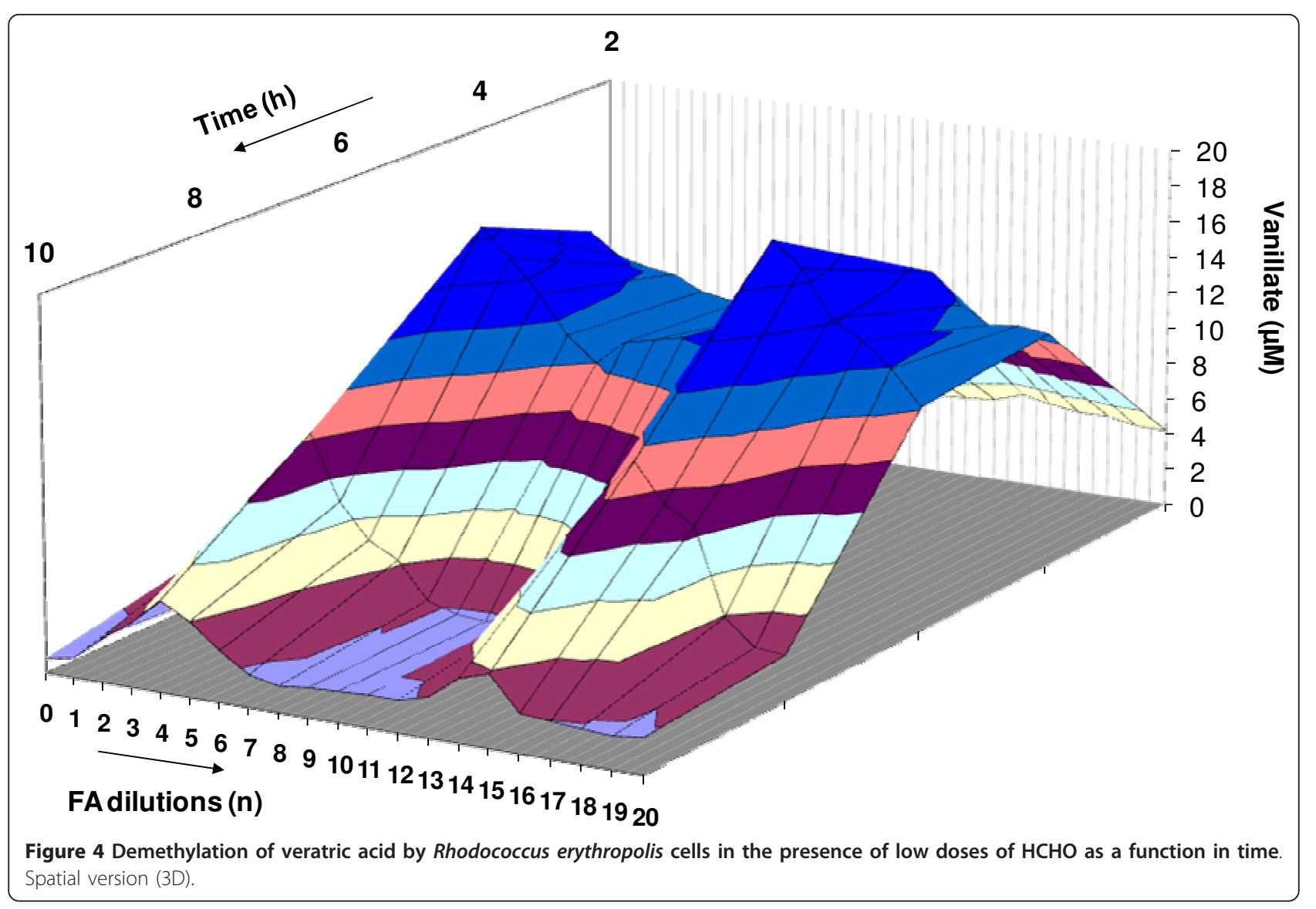

relationship between the periodic reconstruction of the pool of veratric acid and the amount of vanillic acid in the incubation medium. The double number of veratric acid maxima pointed to the double frequency of methylation of vanillic acid, compared with demethylation of veratric acid (Figure 6). Incubation of cells with FA dilutions in the water series caused more chaotic changes in the level and the renewal of veratric acid (Figure 7). Nonetheless, the character of the changes remained the same.

\section{Determination of NADH oxidase activity in Rh. \\ erythropolis cells}

Changes in NADH oxidase activity were observed during incubation of Rh. erythropolis cells with both the water and the ethanol HCHO dilution series. For easier comparison of the distribution of the maxima and minima of demethylase and oxidase activities, the level of NADH oxidase activity was plotted in Figure 8 and 9 against DASA values from Figure 2 corresponding to demethylase activity. It was found that oxidase oscillations were less regular than demethylation processes. It was also observed that not all maxima were positioned opposite one another. A particular lack of regularity was observed in the action of the dilutions of the water series.
Analysis of morphological changes in Rh. erythropolis cells under the influence of high $\mathrm{HCHO}$ dilutions

A comparison was made among microscopic images of the morphology of Rh. erythropolis cells incubated with selected FA dilutions (Figure 10). The images provided further information on the effect of $\mathrm{HCHO}$ dilutions on the morphology of the bacterial cells. It was observed that the dilutions with maximum potency increased the volume and size of intracellular vacuoles, in contrast to the least potent dilutions, at which the vacuoles tended to disappear. The control cell material, which had no contact with veratric acid, showed the presence of a large number of small vacuoles, which markedly differed from the more numerous and considerably larger vacuoles found in the cells incubated with the FA dilutions showing maximum 4-O-demethylase activity. This state differed clearly from the image of cells with a low enzymatic activity, where vacuoles were restructured and tended to disappear.

\section{Discussion}

To investigate the regulatory properties of formaldehyde in demethylation processes, a model system of demethylation of veratric acid by $R h$. erythropolis cells, described in our earlier papers $[17,19]$, was used. This biological 

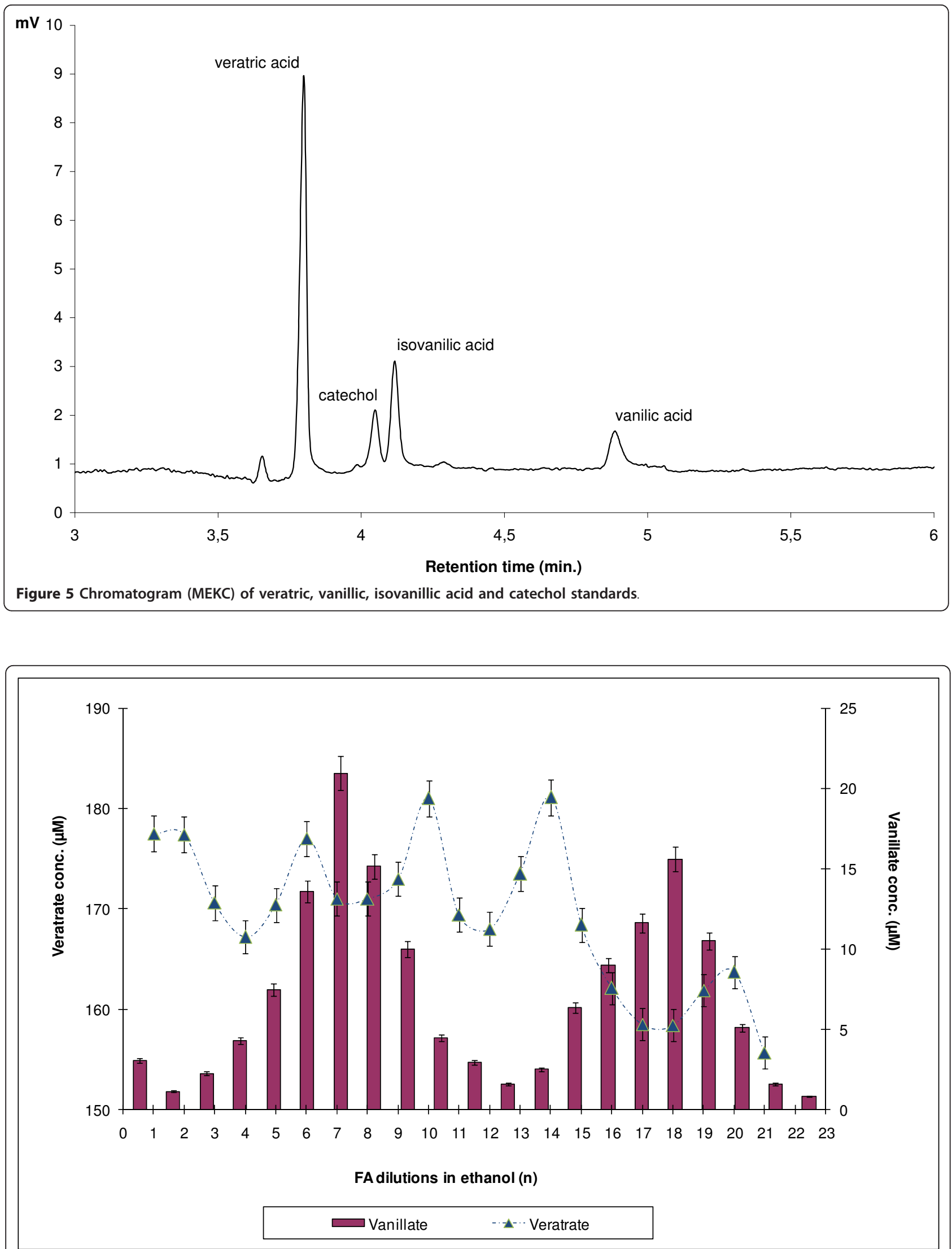

Figure 6 Changes in the level of veratric acid during incubation of formaldehyde with Rh. erythropolis cells in a series of HCHO dilutions in ethanol and the corresponding levels of vanillic acid identified using MEKC. 


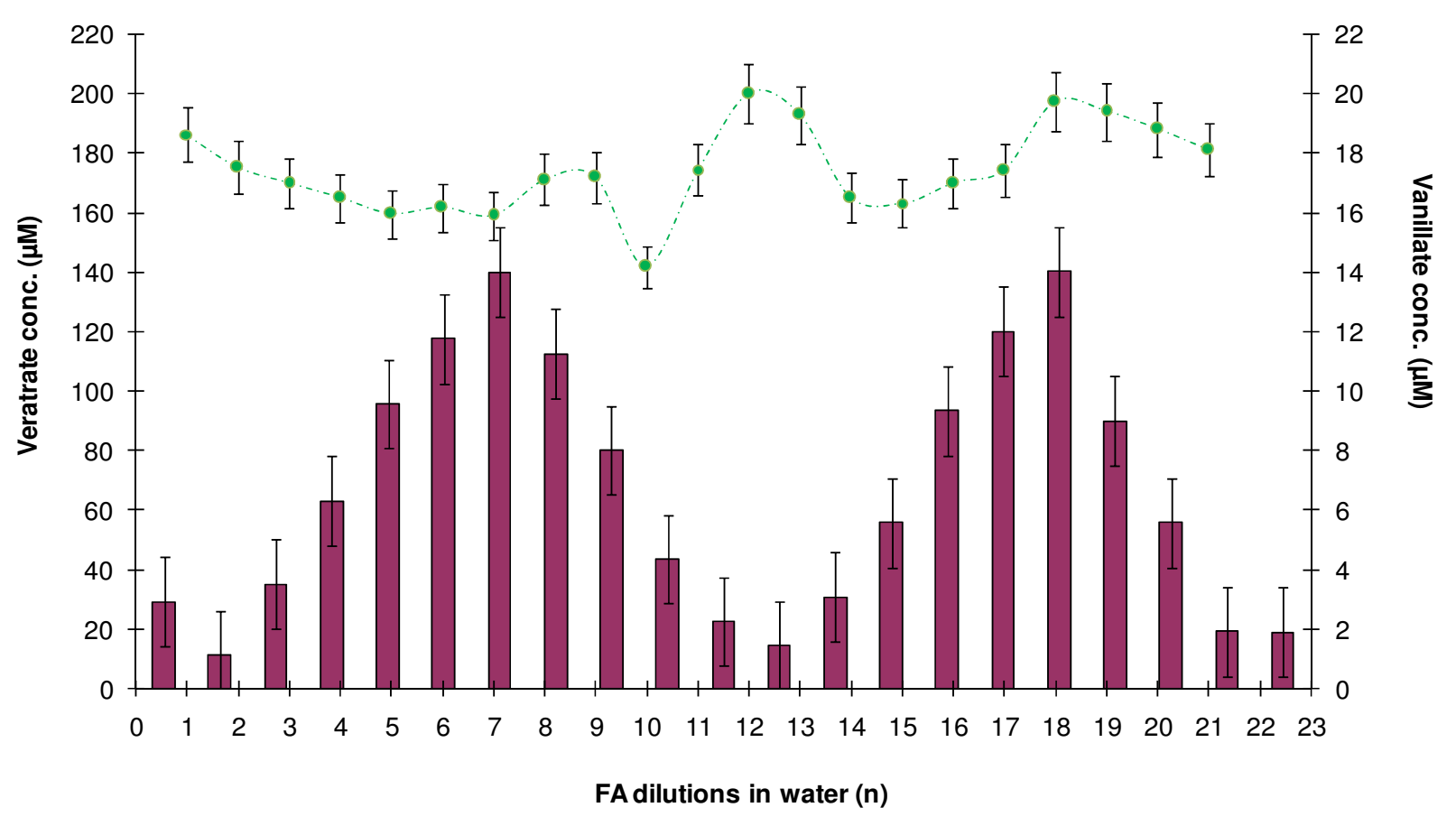

Figure 7 Changes in the level of veratric acid during incubation of formaldehyde with Rh. erythropolis cells in a series of HCHO dilutions in water and the corresponding levels of vanillic acid identified using MEKC.

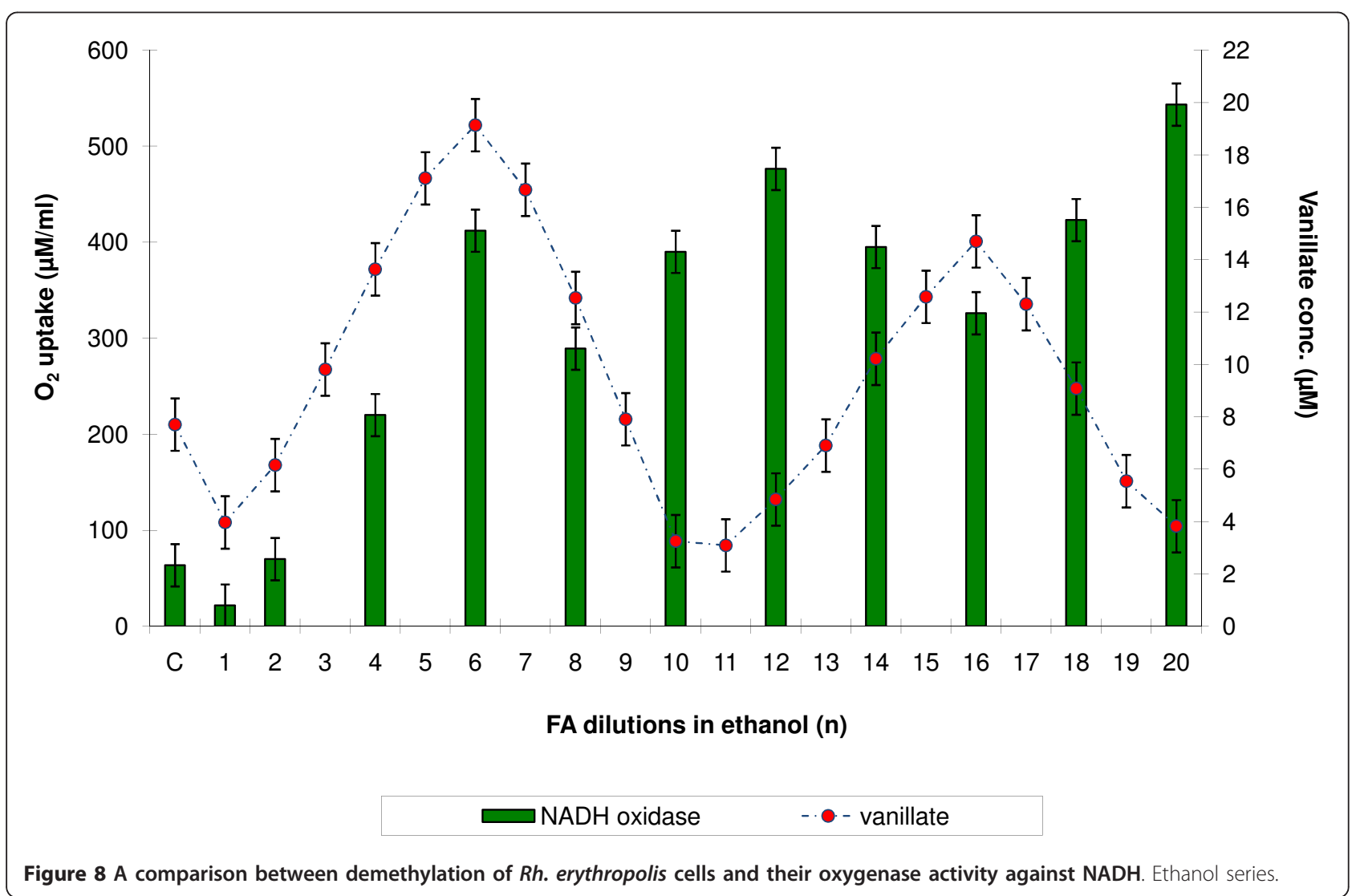




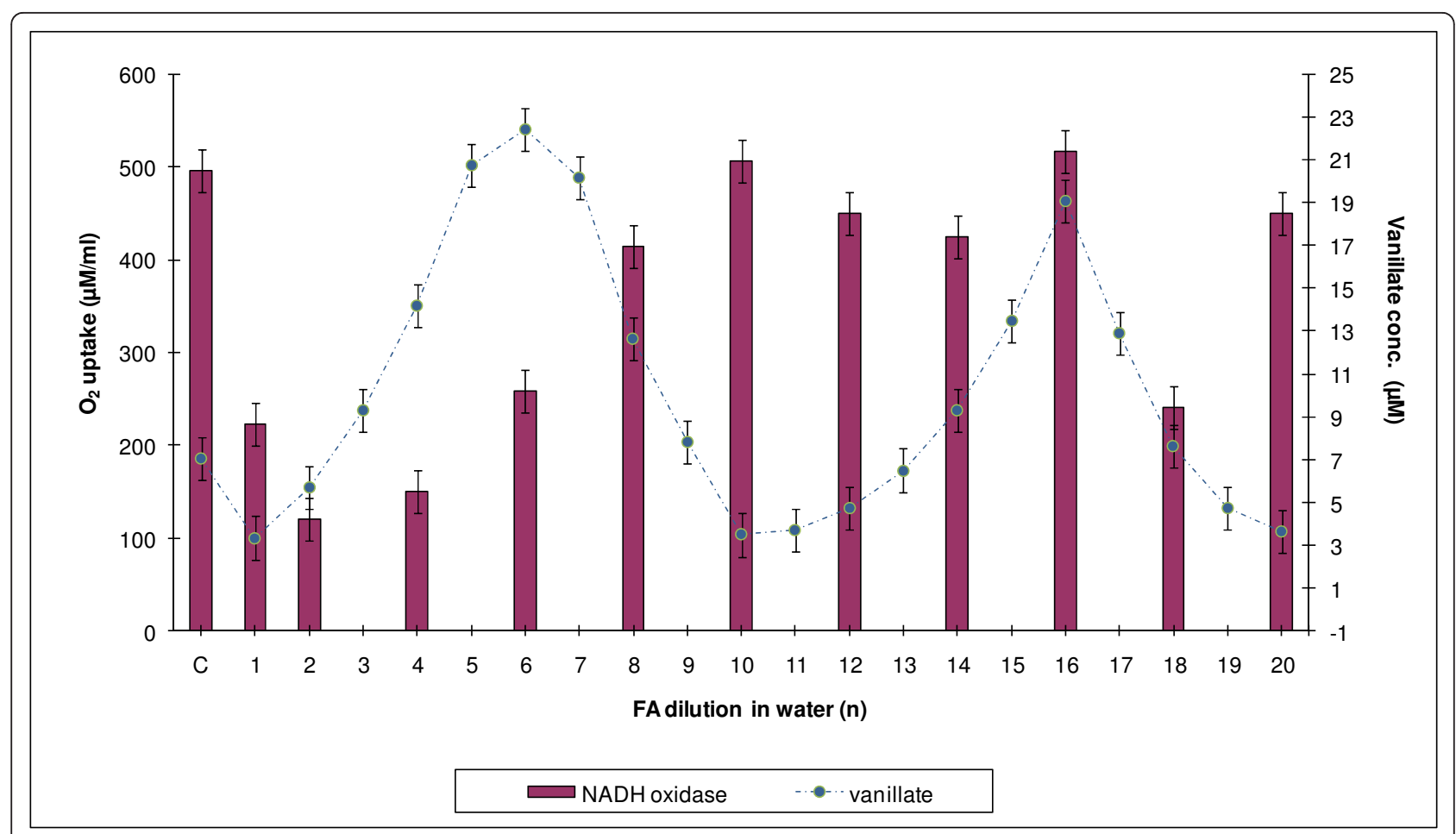

Figure 9 A comparison between demethylation of Rh. erythropolis cells and their oxygenase activity against NADH. Water series.

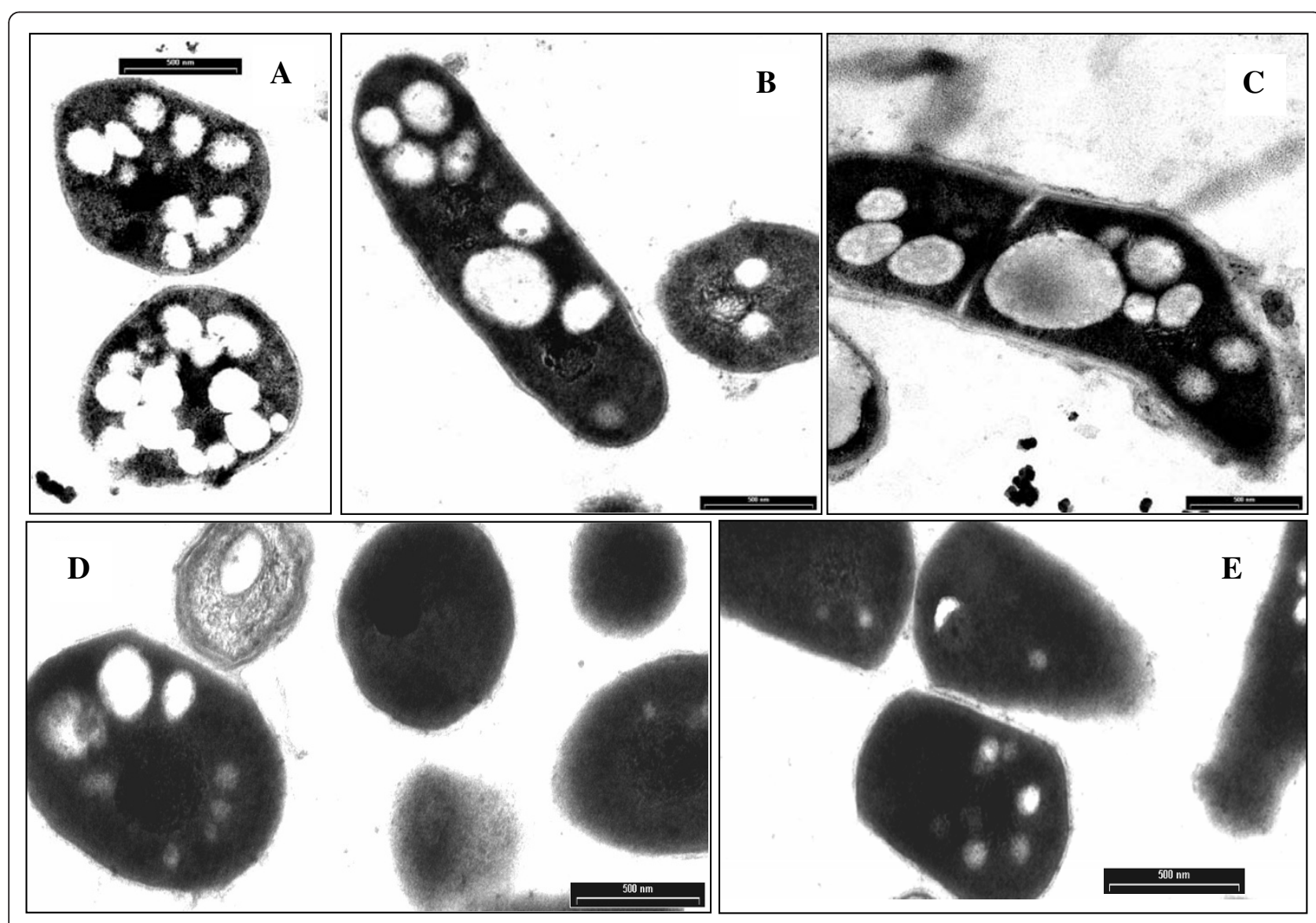

Figure 10 Differences in morphology of Rh. erythropolis cells under the action of very low doses of formaldehyde in $75 \%$ ethanol. Acontrol with ethanol; $B$ and C-maximum of demethylation, $\mathrm{n}=5$ and 15; $\mathrm{D}$ and E-minimum of demethylation, $\mathrm{n}=10$ and 20. 
system is sensitive both to an excess and a lack of FA as well as to normal and excited states of this molecule. The system pointed to 4-O-demethylase as the enzyme responsible for the accumulation of vanillic acid in the incubation medium. The experiments described above showed that the presence of diluted FA in the reaction medium significantly affected the rate of demethylation. The capillary electrophoretic experiments (MEKC) conducted in this study demonstrated that the accumulation of vanillic acid was changed. On the basis of these results, it was possible to choose those FA dilutions which clearly activated or inhibited the activity of 4-Odemethylase and were, accordingly, recorded as maximum or minimum concentrations of vanillic acid in the bacterial culture.

MEKC also enabled a comparison between the concentrations of vanillic and veratric acids. The fluctuations in the concentration of veratric acid showed which FA dilutions caused its renewal. As discussed in our previous paper, the pool of veratric acid is reconstructed spontaneously as a result of non-enzymatic methylation of vanillic acid with the participation of excited FA [17]. Excitation of FA occurs with the participation of reactive oxygen species as a result of veratric acid coming in contact with the bacterial system of NADH oxidase, which generates free radicals (see also [25-27]. In the present study, similar effects of activation of 4-O-demethylase and distinct changes in NADH oxidase were obtained by using appropriate FA dilutions prepared by successive iterations in $75 \%$ ethanol connected with shaking. It is highly probable that shaking (i.e., enhancing the potential energy of the system) has an effect on the state of excitation of FA, since both 4-O-demethylase and NADH oxidase were activated during incubation with $R h$ cells (Figure 1 ).

The occurrence of the successive maxima of activity, which was a consequence of increasing dilutions,, indicated that the investigated effect was repeatable. Similar relationships had been described earlier for fungal peroxidase and laccase [20], and HR-peroxidase [22,23]. In the present study, the plot of activation of 4-Odemethylase by selected FA dilutions was supplemented with the parameter of time. In two-dimensional (2D) space (Figure 3) was now transformed into a system with a distinctly varied surface visualized in 3D (Figure 4). Observations over time pointed to dynamic aspects of the described changes. They showed that maximum activation of 4-O-demethylase as a result of incubation of selected FA dilutions with $R h$. cells was achieved after 6 hours. Due to the dynamic character of those transformations, the course of demethylation over time resembled the effects described by Calabrese and Baldwin $[28,29]$ as hormesis.

Especially one of the latest works of Calabrese et al. [30] and Szende et al. [31] are worth discussing in the context of the present studies. These two works demonstrate the effect of applying appropriately chosen low doses of resveratrol, now a commercially available diet supplement. Resveratrol is commonly found in nature, e. g., large amounts of it are present in red grapes. Resveratrol is a natural stilbene in a trans configuration, which shows strong detoxifying properties. Therefore, it is very probable that these detoxifying effects are the result of intensive elimination of FA [32] even when resveratrol is present in very low doses [31]. The results obtained in the present study prove that also the enzymes connected with methylation/demethylation metabolism, 4O-demethylase and NADH oxidase, are sensitive to low and very low doses of FA.

Just as in our previous papers [22,23], it was demonstrated in this study that the effect of diluted effectors has a fractal character and their periodic action is independent of the Avogadro constant. If we had not exceeded this value, we would not have been able to demonstrate the presence of further maxima of occurrence of vanillic acid, which required further dilution beyond $10^{-24}$ (Figure 2). Using dilutions ranging from C1 $\left(100^{-1}\right)$ to $\mathrm{C} 20\left(100^{-20}\right)$, we were able to show two maxima of accumulation of vanillic acid at a 10-iteration interval (20 decimal places). After those 10 steps, the level of activity returned to the previous state. This suggests the existence of a specific cycle for those processes requiring 10 iterations. The fluctuations in demethylation activity bear a considerable resemblance to the frequency of the transformations observed previously for the action of phenol on the activity of plant peroxidase HRP [22,23] and fungal laccase [20]. It is also important to note that methylation processes reproducing veratric acid occur more frequently-every five iterations (Figure 6).

Active FA dilutions also triggered a response in live Rh. erythropolis cells. When coming in contact with very low doses of FA, the cells reacted with clear changes in their morphology, both with respect to the quantity and quality of vacuoles. The number and size of the vacuoles was visibly higher in cells incubated with those FA dilutions which stimulated a high 4-O-demethylase activity. This was connected with an increase in the concentration of vanillic acid in the incubation medium. At the same time, minimum states of demethylase activity correlated in the cells with the disappearance of vanillate and simultaneous renewal of veratric acid and were characterized by a drop in the number of vacuoles. Almost the same relationships had been described in an earlier study [17], in which the number of vacuoles was shown to increase in cells which released large amounts of oxygen (oxidative burst). This was also connected with a decrease in the amount of vanillic acid. The present data confirmed the previous finding that the 
demethylation processes occurring during the use of FA dilutions strictly correlated with changes in cell morphology.

In both this and our previous studies, formaldehyde seemed to be a significant regulator of demethylation. However, while in the earlier papers the regulatory effect of FA had been induced endogenously, here FA was used as an exogenous factor of variable concentration. Whereas previously demethylation had been initiated by a single addition of veratric acid to a nongrowing bacterial culture, in the present study, the same process depended on adding an appropriate FA dilution. Inasmuch as the morphological changes in the cells after a single addition of veratric acid to a bacterial culture are a logical consequence of the gradual decrease in the concentration of substrates in the incubation medium during the reaction, the observation that this process can be carried on by using appropriate FA dilutions as co-substrates seems to be a prelude to acknowledging that living cells can detect the presence of submolecular concentrations of biologically active substances. FA is easily excited as a result of both coming in contact with reactive oxygen species [33,34] and energetic changes in the system [35]. Among reactive oxygen species, $\mathrm{H}_{2} \mathrm{O}_{3}$ seems to be a particularly interesting molecule [36,37]. Its presence could be reflected by changes in a number and size of vacuoles, increased after the treatment of Rhodococcus cells with the selected formaldehyde dilution.

The novelty of this work is that it provides further experimental evidence for the possibility of inducing a biological effect by exposing living cells to the action of highly diluted chemical substances. The mechanism of this phenomenon has not yet been elucidated but according to the papers of Montagnier et al. [38], serial dilution of substances in water correlated with agitation can generate electromagnetic signals in these solutions. Montagnier's experiments with high aqueous dilutions of some bacteria and HIV revealed that DNA and some proteins induced the emission of electromagnetic waves [38]. This was connected with the induction of the emission of electromagnetic waves [38].

We also provided some experimental evidence for this phenomenon. We showed that by carrying out experiments with a series of successive effector dilutions, one can effectively choose those dilutions which have a distinctly strong biological action. This possibility of using a non-linear phenomenon to predict the behavior of model biological systems leads to rational design of new research systems and their verification on the basis of the ones that already exist. Such a double verification of the results is a domain of synthetic biology, which places a large emphasis on rational design of new systems and intensive use of model techniques for predicting the behavior of systems and optimization of their operation.

The changes in time of the solution's $\mathrm{n}=0$ activity are not clear yet and an autooscillatory reaction can be taken into the consideration. In the future we are going to test $\mathrm{n}=0$ solution to check a possibility of autooscillatory nature of such a reaction.

\section{Acknowledgements}

This work was supported by the Polish Scientific Project BS/UMCS

\section{Authors' contributions}

EM projected and coordinated the experiments. MPC conducted the NADH oxidase activity assay. MG performed MEKC analysis. JKR prepared the biological material and conducted the demethylase activity assay. AJW participated in the sequence alignment. All authors read and approved the final manuscript.

\section{Competing interests}

The authors declare that they have no competing interests.

Received: 6 July 2011 Accepted: 21 November 2011

Published: 21 November 2011

\section{References}

1. Manninger $K$, Csösz M, Tyihak E: Induction of resistance of wheat plants to pathogens by pretreatment with $\mathrm{N}$-methylated substances. Acta Biol Hungar 1998, 49:275-280.

2. Trezl L, Hullan L, Szarvas T, Csiba A, Szende B: Determination of endogenous formaldehyde in plants (fruits) bound to L-arginine and its relation to the folate cycle, photosynthesis and apoptosis. Acta Biol Hungar 1998, 49:253-264.

3. Peterson $\mathrm{CL}$, Laniel MA: Histones and histone modifications. Curr Biol 2004, 14:R546-551.

4. Gupta S, Kim SeY, Artis S, Molfese DL, Schumacher A, Sweatt JD, . Paylor RE, Lubin FD: Histone methylation regulates memory formation. J Neurosci 2010, 30:3589-359.

5. Weis RM, Chasalown S, Koshland DE Jr: The role of methylation in chemotaxis: an explanation of outstanding anomalies. J Biol Chem 1990, 265:6817-6826.

6. Siqueira JO, Nair MG, Hammerschmidt R, Safir GR: Significance of phenolic compounds in plant-soil-microbial systems. Crit Rev FoodSci 1991, 10:63-121.

7. Akio S, Kenji N, Ryuichiro K, Yoshihiro N: $\mathbf{O}^{-}, \mathbf{m}$-and $p$-Hydroxybenzoate degradative pathways in Rhodococcus erythropolis. FEMS Microbiol Lett 1995, 125:31-35.

8. Hagel JM, Facchini PJ: Biochemistry and occurrence of O-Demethylation in Plant Metabolism. Frontiers in Plant Physiology 2010, 1:Art 14.

9. Tyihak E, Albert L, Nemeth ZI, Katay Gy, Kiraly-Veghely Z, Szende B: Formaldehyde cycle and the natura formaldehyde generators and capturers. Acta Biol Hangar 1998, 49:225-238.

10. Malarczyk E: Substrate-induction of veratric acid O-demethylase in Nocardia sp. Acta Biochim Pol 1984, 31:383-95

11. Larkin MJ, Kulakov LA, Allen CCR: Biodegradation and Rhodococcusmasters of catabolic versatility. Curr Opin Biotechnol 2005, 16:282-290.

12. Larkin MJ, Kulakov LK, Allen CCR: Biodegradation by members of the genus Rhodococcus: Biochemistry, physiology, and genetic adaptation. Adv Appl Microbiol 2006, 59:1-29.

13. Providenti MA, Mampel J, MacSween S, Cook AM, Wyndham RC: Comamonas testosterone BR6020 possesses a single genetic locus for estradiol cleavage of protocatechuate. J Bacteriol 2001, 147:2157-2167.

14. Providenti MA, O'Brien JM, Ruff J, Cook AM, Lambert IB: Metabolism of isovanillate, vanillate and veratrate by Comamonas testosterone strain BR6020. J Bacteriol 2006, 88: 3862-3869.

15. Malarczyk E, Kochmańska-Rdest J: New aspects of co-regulation of decarboxylation and demethylation activities in Nocardia. Acta Biochim Pol 1990, 37:145-8. 
16. Paździoch-Czochra M, Malarczyk E: Relationships between demethylase activity, formaldehyde and oxygen during incubation of Rhodococcus erythropolis with veratrate. Acta Biol Hung 1998, 49:405-12.

17. Malarczyk E, Pazdzioch-Czochra M: Multiple respiratory bursts as a response to veratrate stress in Rhodococcus erythropolis cells. Cell Biol Int 2000, 24:515-27.

18. Saeki Y, Nozaki M, Matsumoto K: Purification and properties of NADH oxidase from Bacillus megaterium. J Biochem 1985, 98:1433-1440.

19. Paździoch-Czochra M, Malarczyk E, Sielewiesiuk J: Relationship of demethylation processes to veratric acid concentration and cell density in cultures of Rhodococcus erythropolis. Cell Biol Int 2003, 27:325-36.

20. Malarczyk E, Jarosz-Wilkołazka A, Kochmańska-Rdest J: Effect of low doses of guaiacol and etanol on enzymatic activity of fungal cultures. Nonlinearity Biol Toxicol Med 2003, 1:167-178.

21. Malarczyk E, Kochmanska-Rdest J, Jarosz-Wilkolazka A: Influence of very low doses of mediators on fungal laccase activity-nonlinearity beyond imagination. Nonlinear Biomed Phys 2009, 3:10.

22. Malarczyk E, Kochmańska-Rdest J, Paździoch-Czochra M: Effect of Low and Very Low Doses of Simple Phenolics on Plant Peroxidase Activity. Nonlinearity Biol Toxicol Med 2004, 2:129-141.

23. Malarczyk E: Kinetic changes in the activity of HRperoxidase induced by very low doses of phenol. Int I High Dilut Res 2008, 7:3-11.

24. Vianello $A$, Macri $F: N A D(P) H$ oxidation elicits anion superoxide formation in radish plasmalemma vesicles. Biochim Biophys Acta 1989, 980:202-208.

25. Sakamoto M, Komagata K: Aerobic growth of and activities of NADH oxidase and NADH peroxidase in lactic acid bacteria. $J$ Ferment Bioengin 1996, 82:210-216.

26. Higuchi M, Yamamoto Y, Kamio Y: Molecular biology of oxygen tolerance in lactic acid bacteria: Functions of NADH oxidases and Dpr in oxidative stress. J Biosci Bioengin 2000, 90:484-493.

27. Talwalkar A, Kailasapathy K: Metabolic and biochemical responses of probiotic bacteria to oxygen. J Dairy Science 2003, 86:2537-2546.

28. Calabrese EJ, Baldwin LA: Hormesis as a biological hypothesis. Environ Health Perspectives 1998, 106(Suppl 1):357-362

29. Calabrese EJ, Baldwin LA: Hormesis: The dose-response revolution. Annu Rev Pharmacol Toxicol 2003, 43:175-97.

30. Calabrese EJ, Mattson MP, Calabrese V: Resveratrol commonly displays hormesis: occurrence and biomedical significance. Hum Exp Toxicol 2010, 29:980-1015.

31. Szende B, Tyihák E, Király-Véghely Z: Dose-dependent effect of resveratrol on proliferation and apoptosis in endothelial and tumor cell cultures. Exp Mol Med 2000, 32:88-92.

32. Tyihák $E$, Király-Véghely Z: Interaction of trans-resveratrol with endogenous formaldehyde as one basis of its diverse beneficial biological effects. Bulletin de l'OIV 2008, 81:65-74.

33. Saito Y, Nishio K, Yoshida Y, Niki E: Cytotoxic effect of formaldehyde with free radicals via increment of cellular reactive oxygen species. Toxicology 2005, 210:235-45.

34. Szende $B$, Tyihák E: Effect of formaldehyde on cell proliferation and death. Cell Biol Intern 2010, 34:1273-82.

35. Rescigno TN, Lengsfield BH III, McCurdy CW: Electronic excitation of formaldehyde by low-energy electrons: A theoretical study using the complex Kohn variational method. Phys Rev A 1990, 41:2462-2467.

36. Tyihák E, Mincsovics E, Kátay G, Király-Véghely Z, Móricz ÁM, Ott PG BioArena: An unlimited possibility of biochemical interactions in the adsorbent layer after chromatographic separation. J Planar Chromatogr 2008, 21:15-20.

37. Tyihák E, Mincsovics E: Review: Forced-Flow Planar Liquid Chromatographic Techniques (After Twenty-Two Years). J Planar Chromatogr 2010, 23:382-395.

38. Montagnier L, Aïssa J, Ferris S, Montagnier J-L, Lavalléee C: Electromagnetic signals are produced by aqueous nanostructures derived from bacterial DNA sequences. Interdisciplinary Sciences: Computational Life Sciences 2009, $1: 81-90$

doi:10.1186/1753-4631-5-9

Cite this article as: Malarczyk et al:: Nonlinear changes in the activity of the oxygen-dependent demethylase system in Rhodococcus erythropolis cells in the presence of low and very low doses of formaldehyde. Nonlinear Biomedical Physics 2011 5:9.

\section{Submit your next manuscript to BioMed Central and take full advantage of:}

- Convenient online submission

- Thorough peer review

- No space constraints or color figure charges

- Immediate publication on acceptance

- Inclusion in PubMed, CAS, Scopus and Google Scholar

- Research which is freely available for redistribution 